\title{
DOES GENDER INFLUENCE FARM HOUSEHOLDS' DECISION TO ADOPT TECHNOLOGY AND COMMERCIAL AGRICULTURE: IMPLICATION FOR HOUSEHOLD FOOD SECURITY IN RURAL BANGLADESH
}

\author{
M. Hossain* \\ Department of Agricultural Economics, Bangladesh Agricultural University \\ Mymensingh-2202, Bangladesh
}

\begin{abstract}
This paper investigates whether gender of household head is associated with the household's decision to adopt technology and commercial agriculture in rural Bangladesh. It further investigates if household food security of the adopters differs significantly on the basis of gender of the household head. By using $\chi^{2}$ test and Cramer's $V$ statistic this paper finds evidence to suggest that adoption of both technology and of commercialisation of agriculture in rural Bangladesh significantly differs between male-headed and female-headed households. The incidence of adoption among the female-led households is low possibly because they are constrained by lack of access to input, credit, and extension services. It is also found that household food security of the adopters improves irrespective of gender of the household head. Thus the policy implication of the study is that technology adoption and commercial farming may have good prospect for improving household food security of rural farm households.
\end{abstract}

\section{INTRODUCTION}

This research is concerned about gender difference in Bangladeshi agricultural households' adoption of technology and commercial agriculture and about implication of such adoption on household food security. Bangladesh is an agricultural country, in which reducing poverty along with ensuring food security are the foremost development priorities (HKI and JPGSPH, 2014). Unfortunately these priorities are further challenged by the country's declining agricultural resource base and vulnerability to climate change. Intensifying agriculture through adoption of technology and commercial farming may play a vital role in ensuring food security in the country. For example, the yield of Boro rice - the principal source of staple food grain in Bangladesh - is about $1.8 \mathrm{t} \mathrm{ha}^{-1}$ for local varieties, $3.8 \mathrm{t} \mathrm{ha}^{-1}$ for modern

*Corresponding author: mahbub@bau.edu.bd 
varieties; whereas it is $4.7 \mathrm{t} \mathrm{ha}^{-1}$ for hybrid Boro (BBS, 2016). This implies that Boro production may be increased approximately by a tonne per hectare by cultivating hybrid varieties. Yet hybrid rice is being grown in only about $6 \%$ of the country's total rice cultivated area (BBS, 2016). Nonetheless about $9.5 \%$ of total domestic rice production comes from hybrid rice (BBS, 2016). These figures clearly underscore the enormous potential of technology-intensive hybrid crops for increasing domestic food production in Bangladesh.

Hybrid crop cultivation is technology-intensive as well as capital intensive. Thus its adoption depends on farmers' solvency; however, farming communities in Bangladesh are disproportionately represented by marginal and small farmers $(84.4 \%$ of all farm households) (BBS, 2010) who are generally resource poor. Accordingly they have low endowment for adopting technology and capital intensive crops or commercial oriented farming practices. Studies that have documented factors which underlie farm households' decision to adopt modern agricultural practices highlight two broad factors: household head's socioeconomic characteristics and institutional facilities. A study in Nepal has revealed that education, extension services, and seed access play significant role in households' technology adoption decisions. Another study has documented that adoption of modern rice varieties can be explained by age and education of household head along with access to extension services (Ghimire and Huang, 2016). A study in Ghana showed that farm households' technology adoption decisions depend on farmers' socioeconomic circumstances and institutional effectiveness (Akudugu et al., 2012).

The concern over adoption of technology or commercialisation in Bangladesh has been stemming from the fact that the incidence of female-headed households is rising in the country. In 1996 the share of female-headed households were about 3.5\% which rose to $4.3 \%$ in 2008 and it further increased to $7.2 \%$ in 2013 (BBS, 2015, 2016). It implies that more women are becoming directly engaged in food production compared to the past. Nonetheless women in Bangladesh are often constrained by lack of credit, lack of information, and inaccessibility to institutional services. Moreover preference for growing a particular crop or a variety may differ on the basis of gender (Mehar et al., 2017). In such a context, it may be worth investigating whether gender of household head has any influence on adoption of technology and commercial agriculture in farm households of rural Bangladesh. Eliciting such evidence and investigating whether adoption of technology and commercialisation improve household food security of the farm households are the key interest of this study.

\section{DISCUSSIONS}

For empirical analysis this study uses data from the Bangladesh Integrated Household Survey 2012, which contains information on types of crops grown by the households and on household food consumption diversity. A total of 3,409 agricultural 
households of the BIHS constitute the sample for this study, of which 199 households are female headed.

'Technology adoption' is defined as whether or not a household cultivates hybrid variety of any crops. If the household cultivates hybrid variety of any crop then the value 1 is assigned to indicate that the household is an adopter of technology.

Commercial farming is meant to indicate whether the households grow any cash crops. In Bangladesh context cash crops generally include maize, fibre crops, pulses, oilseeds, potatoes, sugarcane and tobacco. Thus the variable 'cash crop' is defined as whether or not a household grows any of the above cash crops: the value 1 is assigned if the household grows and otherwise 0 .

In order to measure the variable 'food security' household dietary diversity score (HDDS) is used in this study. The HDDS better tells about both the quantitative and the qualitative aspects of a household's diet (Swindale and Bilinsky, 2006). The BIHS has collected information on what food groups a household had consumed over the past week. The food groups considered are (i) cereals, (ii) roots and tubers, (iii) vegetables, (iv) meat, (v) eggs, (vi) fish, (vii) dairy, (viii) pulses, (ix) oils, (x) fruits, (xi) sugar, and (xii) miscellaneous. For consuming a particular type of food the value 1 is assigned and otherwise 0 . The values are then summed over the 12 food groups, which ultimately generates the household dietary diversity score. It follows that HDDS ranges between 0 and 12 and a higher HDDS reflects greater variation in the household's diets. Based on the variability of the HDDS the sample is split into terciles. Then the mean HDDS of top-tercile is taken as a threshold: a HDDS below the threshold will imply a lack of variation in the household's diet and thus regarded as food insecure. On the other hand, a HDDS which is equal to or higher than the threshold value will mean the household's diet is sufficiently diverse and hence the household is food secure. The variable 'food security' takes the value 1 to denote a household is food secure and otherwise 0. In the sample, among the 460 hybrid crop growing households 207 households are categorised as food secure on the basis of the of the HDDS. Of the food secure households, only 7 households are headed by a woman.

At first this paper presents bi-variate distribution of the sample in respect of technology adoption, cash crop cultivation, and food security across gender of household head. Afterwards in order to test whether or not the observed variation in the distribution of the households with respect to technology adoption and commercialisation across gender is statistically significant, the $\chi^{2}$ test is performed. The $\chi^{2}$ test statistic is computed as $\chi^{2}=\frac{\sum\left(f_{o}-f_{t}\right)^{2}}{f_{t}}$ with (r-1)(c-1) degree of freedom. The term $f_{o}$ means observed frequency, $f_{t}$ means expected frequency, $\mathrm{r}$ means the number of rows, and c means the number of columns. Expected frequency 
$f_{t}$ is computed as $f_{t}=\frac{(\text { Row total })(\text { Column total })}{\text { Total samplesize, } \mathrm{N}}$. The first hypothesis here is that the incidences of technology adoption are not statistically different between maleheaded and female-headed households. The next hypothesis is that among the technology adopters food security is not significantly different between male-headed households and female-headed households. The third hypothesis is set out as the incidences of cash crop cultivation are not significantly different between maleheaded and female-headed households. The last hypothesis is set out as no significant difference in the incidences of food security among the cash crop growing households on the basis of gender of household head.

If the calculated value of $\chi^{2}$ is greater than the tabulated value at a low level of significance then the null hypothesis will be rejected. It is important to note here that the $\chi^{2}$ value does not tell anything about the extent of association between the variables of interest. With a view to finding a comprehensive measure of the degree of association of the adoption indicators with the gender of household head, this research additionally reports Cramer's V statistic. Notably this statistic is capable of quantifying strength of a relationship between two nominal variables. Cramer's V is computed as $V=\sqrt{\chi^{2} / N(k-1)}$ where $\mathrm{N}$ is the sample size, and $\mathrm{k}$ is the smaller of the number of rows and columns. Since in all instances in this paper, the bi-variate distribution table is of $2 \times 2$ dimension, the term k-1 is equal to 1 . The rule of thumb in interpreting the Cramer's $\mathrm{V}$ is that if it ranges between -1 to -0.7 then there is a very strong negative association, -0.7 to -0.3 would mean weak negative association, 0.3 to 0.7 means weak positive association, and finally 0.7 to 1 represents a very strong positive association (Babu and Sanyal, 2009). Any value between -0.3 to 0.3 means no association.

Table 1 shows the comparison of technology adoption and food security status across the gender of the household heads. As can be seen from panel A in Table 1, overall 460 households out of 3,409 households grow hybrid crops. About 14\% male-headed households are technology adopters compared with $8.5 \%$ female-headed households. This result is suggestive of the fact that male-headed households are more likely to adopt modern technology relative to female-headed households. This is so possibly because female-headed households may not have access to critical inputs required for adopting hybrid varieties or because female household heads are generally risk averse in the case of adopting a new technology. In the sample overall $13.50 \%$ households are technology adopters. 
Table 1.Distribution of technology adopters and food secured households across gender of household head

\begin{tabular}{lccccccccc}
\hline \multirow{2}{*}{ Gender } & \multicolumn{3}{c}{ Technology adoption } & & \multicolumn{3}{c}{ Food security } \\
\cline { 2 - 4 } \cline { 7 - 8 } & No & Yes & Total & & No & Yes & Total \\
\hline Female & 182 & 17 & 199 & & 10 & 7 & 17 \\
Male & 2,767 & 443 & 3,210 & & 243 & 200 & 443 \\
Total & 2,949 & 460 & 3,409 & & 253 & 207 & 460 \\
\hline
\end{tabular}

Source: author's calculation

Panel B in Table 1 shows the distribution of the technology adopters in respect of food security across gender of household head. It is evident that among the technology adopters about $45 \%$ male-headed households are food secure compared with about $41 \%$ female-headed households. Panel A and B clearly signifies that fewer female headed households adopt technology and among the adopters the proportion of food insure household is high for female-led households.

Panel A of Table 2 also shows a similar gender difference in the incidence of cash crop cultivation. About $38 \%$ of the male-headed households are found to have grown cash crops compared with about $18 \%$ female-headed households. It is generally very difficult to explain why this is the case from the cross-tabulation results; however, one possibility may be is that female-headed households are disadvantaged in respect of access to markets, agricultural extension service, market information and so on in contrast to male-dominated households.

Table 2. Distribution of cash crop growers and food secured households across gender of household head

\begin{tabular}{lcccccccc}
\hline \multirow{2}{*}{ Gender } & \multicolumn{3}{c}{ Cash crop } & & \multicolumn{3}{c}{ Food security } \\
\cline { 2 - 4 } \cline { 7 - 9 } & No & Yes & Total & & No & Yes & Total \\
\hline Female & 136 & 63 & 3,210 & & 40 & 23 & 63 \\
Male & 1,980 & 1,230 & 199 & & 689 & 541 & 1,230 \\
Total & 2,116 & 1,293 & 3,409 & & 729 & 564 & 1,293 \\
\hline
\end{tabular}

Source: author's calculation

Turning to panel $\mathrm{B}$ of Table 2 it can be observed that among the cash crop growing households, about $44 \%$ male-headed households are food secure compared to $36.51 \%$ of the female-headed households. This again indicates that fewer female-headed households are food secured in comparison with male-headed cash crop growing households. 
Now it is evident from Table 3 that in the case of technology adoption the p-value is smaller than 0.05 which implies that the null hypothesis of no relationship between gender of household head and adoption of hybrid varieties can be rejected. It implies that incidences of technology adoption are significantly different between maleheaded and female-headed households. However the extent of the relationship is very weak as Cramer's V is very low but the negative sign suggests that there is an inverse relationship between them.

Table 3. Results of hypothesis test

\begin{tabular}{l|c|c|c}
\hline \multicolumn{1}{c|}{ Null hypothesis } & $\begin{array}{c}\chi^{2} \\
\text { statistic }\end{array}$ & p-value & $\begin{array}{c}\text { Cramer's } \\
\text { V }\end{array}$ \\
\hline 1. $\begin{array}{l}\text { Technology adoption does not vary between male- } \\
\text { led and female-led households }\end{array}$ & 4.438 & 0.035 & -0.036 \\
$\begin{array}{l}\text { 2. Among the technology adopters food security status } \\
\text { does not vary between male-led and female-led } \\
\text { households }\end{array}$ & 0.104 & 0.747 & -0.015 \\
$\begin{array}{l}\text { 3. } \\
\begin{array}{l}\text { Incidences of cash crop cultivation do not vary } \\
\text { between male- and female headed households } \\
\text { Among the cash crop growers food security status } \\
\text { does not vary between male-led and female-led } \\
\text { households }\end{array}\end{array}$ & 3.530 & 0.060 & -0.032 \\
\hline
\end{tabular}

Source: author's calculation

In the case of food security status of the technology adopters the null hypothesis cannot be rejected because the associated p-value is larger than 0.05 which means that among the adopters of technology there is no significant difference in the food security status across gender of household head. This may also mean that technology adoption does not create any gender differentiated effect on household food security, which is a very good sign as far as food security is concerned. Furthermore the absence of any strong relationship between gender and household food security of the technology adopters is confirmed by the very low Cramer's V.

Moving on to the hypothesis concerning cash crop cultivation, it can be seen that the p-value of the $\chi^{2}$ test barely exceeds 0.05 , which means that the null hypothesis can be rejected at 5 per cent level of significance. However as the p-value is just over 0.05 but less than 0.10 the null hypothesis cannot be rejected at 10 per cent level of significance. Thus by considering a slightly broad level of significance it may be said that there is perhaps some association between cultivation of cash crops and gender of household head with male-led households are more prone to grow cash crops. Nevertheless the small negative Cramer's V indicates that the association is not very strong but there exists an opposite relationship. 
Among the cash crop growers, there is no significant difference as regards food security across gender of household head as the p-value of $\chi^{2}$ is greater than 0.05 . This means that commercialisation of agriculture does not create any gender differentiated effect on household food security. As revealed by the Cramer's V, there is no strong association between food security and gender of household head in the case of cash crop growing households.

\section{CONCLUSION}

The understanding of the linkage between female-headed households and adoption of technology or commercial agriculture is inherently complex. Female-headed households usually have less access to crucial inputs such as land, labour, credit, and extension services. In such a perspective and taking Bangladesh into account, this paper has found evidence to suggest that gender matters for technology adoption and commercialisation of agriculture in the country. For the sake of ensuring food security, which is a top priority of the country, there are practically few other options left other than pursuing cultivation of high-tech hybrid crops. However, on the basis of the findings of this paper it becomes apparent that gender of household head has a strong influence on hybrid crop cultivation in Bangladesh. Male-led farm households are more prone to grow hybrid crops compared to female-led households, which has a policy concern because the share of female-headed households in farming community in Bangladesh has gone up over the past years. In the case of cash crops cultivation, a very similar result of strong influence of gender has been found. The policymakers need to seriously take into account such gender difference and should trigger research as to understand the underlying causes. If the barriers encountered by the female- headed households can be eliminated then food security of those households would considerably improve because this study suggests that once a household adopts technology-intensive or commercial crop cultivation, its food security gets better irrespective of the gender of household head.

\section{REFERENCES}

Akudugu, M.A., Guo, E., and Dadzie, S.K. (2012). Adoption of modern agricultural production technologies by farm households in Ghana: What factors influence their decisions? Journal of Biology, Agriculture and Healthcare, 2(3), 1-14.

Babu, S.C., and Sanyal, P. (Eds.). (2009). Food security, poverty and nutrition policy analysis: Statistical methods and applications (1st ed.). Burlington, MA 01803, USA.

BBS. (2010). Census of Agriculture 2008, Structure of agricultural holding and livestock population Volume 1. Bangladesh Bureau of Statistics, Statistics Division, Ministry of Planning, Government of The People's Republic of Bangladesh, Dhaka.

BBS. (2015). Economic Census. Bangladesh Bureau of Statistics, Ministry of Planning, Government of the People's Republic of Bangladesh, Dhaka. 
BBS. (2016). Yearbook of Agricultural Statistics 2015. Bangladesh Bureau of Statistics, Ministry of Planning, Government of the People's Republic of Bangladesh, Dhaka.

Ghimire, R., and Huang, W.C. (2016). Adoption pattern and welfare impact of agricultural technology. Journal of South Asian Development, 11(1), 113-137.

HKI and JPGSPH. (2014). State of Food Security and Nutrition in Bangladesh 2013. Helen Keller International and James P. Grant School of Public Health, Dhaka.

Mehar, M., Yamano, T., and Panda, A. (2017). The role of gender, risk, and time preference in farmers' rice variety selection in Eastern India. Asian Journal of Agriculture and Development, 14(1), 17-37.

Swindale, A., and Bilinsky, P. (2006). Household Dietary Diversity Score (HDDS) for measurement of household food access: Indicator guide. Food and Nutrition Technical Assistance (FANTA), Washington $\quad$ D. $\quad$ C. https://doi.org/10.1017/CBO978110 7415324.004 